\title{
Pengaruh Biaya Produksi Terhadap Harga Jual Ikan Nila Pada Balai Benih Ikan Lokal (BBIL) Di Desa Cukan Lipai Kecamatan Batang Alai Selatan Kabupaten Hulu Sungai Tengah
}

\section{(Effect of Production Costs of Selling Price Tilapia at Local Fish Seed Center (LFSC) in Cukan Lipai Village Batang Alai Selatan District Hulu Sungai Tengah Regency)}

\author{
Azwar Saihani ${ }^{1)}$ \& Yulia $^{2)}$ \\ Program Studi Agribisnis, Sekolah Tinggi Ilmu Pertanian Amuntai \\ ${ }^{1)}$ Azwar.saihani63@yahoo.com \\ ${ }^{2)}$ yulia@gmail.com
}

\begin{abstract}
ABSTRAK
Penelitian ini bertujuan (i) mengetahui pengaruh biaya produksi terhadap harga jual ikan nila, (ii) bagaimana biaya dikeluarkan untuk produksi ikan pada kegiatan pembenihan ikan di Balai Benih Ikan Lokal (BBIL) di Desa Cukan Lipai Kecamatan Batang Alai Selatan Kabupaten Hulu Sungai Tengah. Metode yang digunakan adalah studi kasus, responden dalam penelitian ini melakukan wawancara dengan karyawan Balai Benih Ikan Lokal (BBIL). Metode analisis data yang digunakan adalah analisis regresi berganda, persamaan hubungan linear antara dua atau lebih variabel bebas sehingga hubungan fungsional antara variabel dependen $(Y)$ dengan variabel bebas $\left(X_{I}, X_{2}, X_{n}\right)$, variabel $X$ sebagai variabel bebas dan variabel $Y$ sebagai variabel dependen Hasil penelitian didapatkan nilai $\left(r^{2}\right)$ yang sebesar 0,374 yang artinya biaya produksi memberikan pengaruh terhadap harga jual sebesar 37,4\%, pada usaha pembenihan ikan nila yang berada di Desa Cukan Lipai Kecamatan Batang Alai Selatan Kebupaten Hulu Sungai Tengah. Pengaruh variabel $(X)$ yaitu biaya produksi terhadap variabel $(Y)$ harga jual adalah sebesar 37,4\%, sedangkan sisanya 62,6\% bisa dipengaruhi oleh variabel lain yang tidak dimasukan kedalam model persamaan.
\end{abstract}

Kata kunci : Biaya, produksi, variabel, harga, jual.

\section{ABSTRACT}

This study aims (i) to know the effect of production costs on the selling price of tilapia, (ii) how the costs are spent on fish production in fish hatchery activities at the Local Fish Seed Center (LFSC) in Cukan Lipai Village, Batang Alai Selatan District, Hulu Sungai Tengah Regency. The method used is a case study, respondents in this study conducted interviews with employees of the Local Fish Seed Center (BBIL). The data analysis method used is multiple regression analysis, linear relationship equation between two or more independent variables so that the functional relationship between the dependent variable $(Y)$ and the independent variable $\left(X_{1}, X_{2}, X_{n}\right), X$ variable as the independent variable and $Y$ variable as the dependent variable The results obtained a value $\left(r^{2}\right)$ of 0.374 which means that production costs have an influence on the selling price of 37.4\%, in tilapia hatchery business in Cukan Lipai Village, Batang Alai Selatan District, Hulu Sungai Tengah Regency. The influence of variable $(X)$ is the production cost of variable $(Y)$ selling price is $37.4 \%$, while the remaining $62.6 \%$ can be influenced by other variables not included in the equation model.

Keywords: Cost, production, variable, price, selling.

\section{PENDAHULUAN}

Harga jual produk dan jasa ditentukan oleh perimbangan permintaan dan penawaran di pasar, sehingga biaya bukan satu-satunya penentu harga jual. Selera konsumen, jumlah pesaing yang memasuki pasar, permintaan dan harga jual yang ditentukan pesaing, merupakan contoh faktor-faktor yang sulit untuk diramalkan, yang mempengaruhi pembentukan harga jual produk di pasar. Satu-satunya yang memiliki kepastian relatif tinggi yang berpengaruh dalam penentuan harga jual adalah biaya. biaya memberikan informasi batas bawah suatu harga jual harus ditentukan. Penentuan harga jual pada umumnya merupakan 
pengambilan keputusan yang menyangkut masa depan. Meskipun harga jual produk sudah terbentuk di pasar, informasi biaya penuh terutama biaya produksi sangat dibutuhkan sebagai titik awal untuk mengurangi ketidakpastian dalam menentukan harga jual produk atau jasa yang akan dibebankan kepada konsumen di masa yang akan datang (Suharno, 2006).

Biaya produksi merupakan dasar yang memberikan perlindungan bagi perusahaan dari kemungkinan kerugian. Kerugian akan mengakibatkan suatu usaha tidak dapat tumbuh dan bahkan akan dapat mengakibatkan perusahaan harus menghentikan kegiatan bisnisnya. Untuk menghindari kerugian, salah satu cara adalah dengan berusaha memperoleh pendapatan yang paling tidak dapat menutup biaya produksi. Dengan demikian, sangat penting memperhitungkan biaya produksi dan menetapkan harga jual produk dengan tepat untuk memberikan perlindungan bagi perusahaan dari kemungkinan kerugian (Suharno, 2006).

Perkembangan produksi ikan nila pada tahun 2013 sebanyak 58.170 ekor, pada tahun 2014 mengalami kenaikan dari tahun sebelumnya sebanyak 62.444 ekor. Permintaan pasar untuk ikan nila cukup tinggi untuk konsumsi pribadi ataupun rumah makan. Oleh karena itu penyediaan benih ikan perlu ditingkatkan agar dapat memenuhi permintaan pasar. Dengan tersedianya benih ikan nila merupakan langkah awal dalam mendukung budidaya pembesaran ikan nila untuk menghasilkan ikan nila konsumsi yang berkualitas memenuhi permintaan pasar

Namun, disamping itu ada kendala yang dihadapi antara lain biaya produksi yang semakin mahal yang menjadikan perusahaan mengalami permasalahan dalam mengatasinya. Mengapa penting memperhitungakan biaya-biaya tersebut karena mengingat Balai Benih Ikan yang ada di Cukan Lipai baru di bangun selama 3 tahun, jadi sangat perlu di lakukan penelitian untuk mampu mengembangkan usaha itu.

Penelitian ini bertujuan

mengetahui pengaruh biaya produksi terhadap harga jual ikan nila, (ii) bagaimana biaya dikeluarkan untuk produksi ikan pada kegiatan pembenihan ikan di Balai Benih Ikan Lokal (BBIL) di Desa Cukan Lipai Kecamatan Batang Alai Selatan Kabupaten Hulu Sungai Tengah

\section{METODE PENELITIAN}

Penelitian dilakukan pada Balai Benih Ikan Lokal yang berlokasi di Desa Cukan Lipai, Kecamatan Batang Alai Selatan, Kabupaten Hulu Sungai Tengah yang dimulai dari bulan Maret sampai dengan bulan Juli 2015.

Penelitian ini menggunakan sumbersumber dari data primer dan sekunder. Data primer diperoleh melalui wawancara langsung dengan karyawan Balai Benih Ikan dengan menggunakan kuesioner yang telah disiapkan sebelumnya.

\section{Analisis Data}

Model analisis data yang digunakan adalah analisis regresi berganda, persamaan linier berganda variabel tergantung di pengaruhi oleh dua atau lebih variabel bebas sehingga hubungan fungsional antara variabel tergantung $(\mathrm{Y})$ dengan variabel bebas $\left(\mathrm{X}_{1}, \mathrm{X}_{2}, \mathrm{X}_{\mathrm{n}}\right)$ secara umum dapat di tulis sebagai berikut:

a) Persamaan Regresi Berganda

$$
\mathrm{Y}=\mathrm{f}\left(\mathrm{X}_{1}, \mathrm{X}_{2}, \mathrm{X}_{\mathrm{n}}\right)
$$

Di mana:

$\mathrm{Y}=$ variabel tergantung (dependent)

$\left(\mathrm{X}_{1}, \mathrm{X}_{2}, \mathrm{X}_{\mathrm{n}}\right)=$ variabel bebas

(independent)

Variabel tergantung dipengaruhi oleh dua atau lebih variabel bebas juga terdapat pengaruh dari variabel yang tidak diteliti (e). Persamaan regresi linier berganda dapat di tulis sebagai berikut:

$$
\mathrm{Y}=\mathrm{a}+\mathrm{b}_{1} \mathrm{X}_{1}+\mathrm{b}_{2} \mathrm{X}_{2}+\mathrm{b}_{\mathrm{n}} \mathrm{X}_{\mathrm{n}}+\varepsilon
$$

Keterangan

$\mathrm{Y}=$ harga jual ( Variabel tergantung)

$\mathrm{a}=$ Intersep (Konstant)

$b_{1}=$ Koefisien regresi untuk $X_{1}$

$\mathrm{b}_{2}=$ Koefisien regresi untuk $\mathrm{X}_{2}$ 
$\mathrm{b}_{\mathrm{n}}=$ Koefisien regresi untuk $\mathrm{X}_{\mathrm{n}}$

$\mathrm{X}_{1}=$ Variabel bebas pertama

$\mathrm{X}_{2}=$ Variabel bebas kedua

$\mathrm{X}_{\mathrm{n}}=$ Variabel bebas ke $\mathrm{n}$

$\varepsilon=$ Nilai residu

Regresi linier berganda digunakan untuk mengetahui pengaruh biaya produksi terhadap harga jual. Model di linierkan menggunakan logaritma natural menjadi regresi linier berganda sebagai berikut:

$\operatorname{Ln} Y=\operatorname{Ln} b_{1} X_{1}+\operatorname{Ln} b_{2} X_{2}+\operatorname{Ln} b_{3} X_{3}+\varepsilon$

b) Uji t-statistik

Uji $\mathrm{t}$ digunakan untuk menguji koefisien regresi secara parsial dari variabel independennya. Nilai t hitung masing-masing koefisien regresi dapat diketahui dari hasil penghitungan komputer.

Untuk menentukan nilai t-statistik tabel ditentukan tingkat signifikasi 5\% dengan df $=(n-k-1)$ dimana $n$ adalah jumlah observasi dan $\mathrm{k}$ adalah jumlah variabel termasuk intersep dengan kriteria uji adalah:

Jika t hit > t tabel, maka Ho ditolak

Jika $t$ hit $<\mathrm{t}$ tabel, maka Ho diterima

Hipotesisnya yaitu :

$$
\text { Ho : } \beta 1=0
$$

Tidak terdapat pengaruh yang signifikan dari variabel independen (X) terhadap variabel dependen $(\mathrm{Y})$

$$
\mathrm{H}_{1}: \beta 1 \# 0
$$

Terdapat pengaruh yang signifikan dari variabel independen $(\mathrm{X})$ terhadap variabel dependen (Y).

c) Uji F-statistik

Nilai F hitung digunakan untuk menguji ketepatan model. Uji F ini sering juga disebut sebagai uji simultan, untuk menguji apakah variabel bebas yang digunakan dalam model mampu menjelaskan perubahan nilai variabel tergantung atau tidak. Untuk menyimpulkan apakah model termasuk dalam kategori cocok (fit) atau tidak, kita harus membandingkan nilai $\mathrm{F}$ hitung dengan nilai $\mathrm{F}$ tabel dengan derajat bebas: df: $\alpha,(\mathrm{k}-1),(\mathrm{n}-\mathrm{k})$. Untuk menghitung besarnya nilai $\mathrm{F}$ hitung digunakan formula: $F=\frac{R^{2} /(k-1)}{1-R^{2} /(n-k)}$ d) Koefisien Determinasi

Ukuran statistik yang dapat menggambarkan hubungan antara suatu variabel dengan variabel lain adalah koefisien determinasi dan koefisien korelasi. Koefisien determinasi diberi simbol $\left(\mathrm{r}^{2}\right)$ dan koefisen korelasi diberi symbol r. Koefisien determinasi adalah salah satu nilai statistik yang dapat digunakan untuk mengetahui apakah ada hubungan pengaruh antara dua variabel.

Koefisien determinasi $\left(\mathrm{r}^{2}\right)$ dari hasil regresi sederhana menunjukkan tingkat kejelasan yang dapat diberikan oleh model tersebut terhadap perubahan variabel dependen. Secara umum nilai $\mathrm{r}^{2}$ terletak pada nilai 0 sampai dengan $1\left(0<\mathrm{r}^{2}<1\right)$. Nilai koefisien determinasi menunjukkan persentase variasi nilai variabel dependen yang dapat dijelaskan oleh persamaan regresi yang dihasilkan.

Semakin mendekat nol besarnya koefisien determinasi $\left(\mathrm{r}^{2}\right)$ suatu persamaan regresi, semakin kecil pula pengaruh semua variabel independen terhadap nilai variabel dependen (dengan kata lain semakin kecil kemampuan model dalam menjelaskan perubahan nilai variabel dependen). Sebaliknya, semakin mendekat satu besarnya koefisien determinasi $\left(\mathrm{r}^{2}\right)$ suatu persamaan regresi, semakin besar pula pengaruh semua variabel independen terhadap nilai variabel dependen. Koefisien determinasi dapat dirumuskan sebagai berikut:

$$
\mathrm{R}^{2}=1-\frac{\mathrm{RSS}(\mathrm{n}-\mathrm{k})}{\mathrm{TSS}(\mathrm{n}-1)}
$$

Dimana:

$$
\begin{array}{ll}
\mathrm{RSS} & =\text { Jumlah kuadrat nilai sisa } \\
\mathrm{TSS} & =\text { Total jumlah kuadrat } \\
\mathrm{n} & =\text { Jumlah observasi } \\
\mathrm{k} & =\text { Jumlah parameter }
\end{array}
$$

\section{HASIL DAN PEMBAHASAN}

\section{Hasil Persamaan Regresi Berganda}

Hasil persamaan regresi linier berganda dengan menggunakan program SPSS versi 17,0 pada penelitian ini diperoleh persamaan regresi yang 
menyatakan persamaan pengaruh biaya

produksi (X) terhadap (Y) sebagai berikut:

Tabel 1. Analisis pengaruh biaya produksi terhadap harga jual

\begin{tabular}{lccc}
\hline \multicolumn{1}{c}{ Variabel } & Koefisien regresi & t-hitung & Sig \\
\hline Konstanta & -2.520 & -.158 & .878 \\
Induk Ikan & .218 & 1.547 & .160 \\
Pakan Ikan & .166 & 1.156 & .281 \\
Upah Pegawai & .177 & .134 & .896 \\
\hline
\end{tabular}

Keterangan: $\quad=<0,05$ (berpengaruh nyata)

$=>0,05$ (tidak berpengaruh nyata)

Hasil analisis regresi tersebut diperoleh model regresi untuk menyatakan persamaan pengaruh biaya produksi (X) terhadap harga jual (Y) yaitu:

$$
\begin{aligned}
\mathrm{LnY} & =-2.520+0,218 \operatorname{LnX} 1+0,166 \operatorname{Ln} \mathrm{X}_{2} \\
& +0,177 \operatorname{Ln} \mathrm{X}_{3}
\end{aligned}
$$

Dilihat dari Tabel 1 hasil perhitungan nilai koefisien konstanta adalah sebesar 2.520 dengan t-hitung sebesar $-0,158$ dan nilai signifikan sebesar 0,878. tconstant digunakan untuk mengetahui apakah intercept tersebut signifikan atau tidak. Namun nilai intercept biasanya tidak diuji, yang diuji adalah nilai tkoefisien regersinya. $\mathrm{t}$-constant dihitung dengan formula sebagai berikut:

$$
\begin{aligned}
\mathrm{t} \text {-constant } & =\frac{\text { Unstandardized coefficients }}{\text { Standardized coefficients }} \\
& =\frac{-2,520}{15,915} \\
& =-0,158
\end{aligned}
$$

Koefisien induk ikan sebesar 0,218 nilai t-hitung 1,547 dan nilai signifikan 0,160. Koefisien pakan ikan sebesar 0,166 dengan nilai t-hitung 1,156 dan nilai signifikan sebesar 0,281. Koefisien upah pegawai yang sebesar 0,177 dengan nilai t-hitung 0,134 dan nilai signifikan sebesar 0,896 . Sedangkan nilai t tabel dari t onetilled dan two-tilled dengan taraf signifikan 0,05 adalah sebesar 1,664.

\section{Induk Ikan (XI)}

Koefisien induk ikan sebesar 0,218 nilai t-hitung 1,547 lebih kecil dari nilai ttabel yang sebesar 1,664 $(1,547<1,664)$ dan nilai signifikan 0,160 lebih besar dari nilai alpha $5 \%(0,160>0,05)$. Maka kesimpulan yang diambil adalah $\mathrm{H}_{0}$ diterima dan $\mathrm{Ha}$ ditolak yang artinya bahwa Induk Ikan tidak berpengaruh nyata secara parsial terhadap harga jual ikan nila.

\section{Pakan Ikan $\left(\mathbf{X}_{2}\right)$}

Koefisien pakan ikan sebesar 0,166 dengan nilai t-hitung 1,156 lebih kecil dari nilai t-tabel yang sebesar 1,664 (1,156 < 1,664) dan nilai signifikan sebesar 0,281 lebih besar dari nilai alpha 5\% $(0,281>0,05)$. Dapat disimpulkan $\mathrm{H}_{0}$ diterima dan Ha ditolak yang berarti Pakan Ikan juga tidak berpengaruh nyata secara parsial terhadap harga jual ikan nila.

\section{Upah Pegawai $\left(\mathrm{X}_{3}\right)$}

Koefisien upah pegawai yang sebesar 0,177 dengan nilai t-hitung 0,134 lebih kecil dari nilai t-tabel yang sebesar 1,664 $(0,134<1,664)$ dan nilai signifikan sebesar 0,896 lebih besar dari nilai alpha $5 \%(0,896>0,05)$. Jadi kesimpulannya $\mathrm{H}_{0}$ diterima dan $\mathrm{Ha}$ ditolak yang artinya hal ini telah menunjukan bahwa upah pegawai tidak berpengaruh nyata secara parsial terhadap harga jual ikan nila.

\section{Uji Statistik F}

Nilai $F$ hitung dengan nilai $F$ tabel dengan derajat bebas: df: $\alpha,(\mathrm{k}-1),(\mathrm{n}-\mathrm{k})$. Untuk menghitung besarnya nilai $F$ hitung digunakan formula:

$$
\begin{aligned}
& F=\frac{R^{2} /(k-1)}{1-R^{2} /(n-k)} \\
& F=\frac{\text { Mean Square Regression }}{\text { Mean Square Residual }}=\frac{0,197}{0,124} \\
& F=1,592
\end{aligned}
$$


Hasil pengujian dengan menggunakan uji $\mathrm{F}$ memperlihatkan nilai $\mathrm{F}$ hitung sebesar 1,592 dengan nilai sig 0,266 . Melihat pada tabel $\mathrm{F}$ dengan nilai 3,028 berarti nilai $\mathrm{F}$ hitung lebih kecil dari nilai F-tabel hal ini menyatakan bahwa semua variabel bebas $(\mathrm{X})$ biaya produksi secara simultan tidak berpengaruh nyata terhadap variabel tidak bebas (Y) harga jual.

\section{Koefisien Determinasi $\left(\mathbf{R}^{\mathbf{2}}\right)$}

Koefisien determinasi $\left(\mathrm{r}^{2}\right)$ merupakan besarnya kontribusi variabel bebas (X) terhadap variabel tergantungnya (Y). Semakin tinggi nilai koefisien determinasi maka semakin tinggi variabel bebas dalam menjelaskan variasi perubahan pada variabel tergantungnya.

Koefisien determinasi $\left(\mathrm{r}^{2}\right)$ dari hasil regresi sederhana menunjukan tingkat kejelasan yang dapat diberikan oleh model tersebut terhadap perubahan variabel dependen. Dengan melihat hasil SPSS statistics versi 17.0 data editor dari model summary dapat diketahui bahwa nilai $\left(\mathrm{r}^{2}\right)$ yang sebesar 0,374. Dengan nilai koefisien determinasi $\left(\mathrm{r}^{2}\right)$ yang sebesar 0,374 yang berarti jauh dari angka satu, menunjukan bahwa biaya produksi tidak berpengaruh terhadap harga jual.

Pengaruh variabel $(\mathrm{X})$ yaitu biaya produksi terhadap variabel (Y) harga jual adalah sebesar $37,4 \%$, sedangkan sisanya
$62,6 \%$ bisa dipengaruhi oleh variabel lain yang tidak dimasukan kedalam model persamaan.

\section{Penghitungan Hasil Biaya Produksi dan Harga Jual}

Sistem akuntansi biaya sangat berguna bagi manajemen dalam berbagai kondisi. Salah satu bidang yang manajemennya dibantu oleh akuntansi biaya adalah penetapan harga-harga. Manajemen dapat menetapkan hargaharga dengan lebih mudah dan meyakinkan, karena memiliki informasi yang akurat mengenai biaya-biaya atau produk yang dijual (Sadeli dan Siswanto, 2004).

Biaya produksi dapat diartikan sebagai pengorbanan sumber ekonomi untuk menentukan harga pokok yang digunakan dalam rangka memperoleh penghasilan dan akan dipakai sebagai pengurang penghasilan (Supriyono, 1999).

\section{Biaya Produksi}

Pengeluaran biaya produksi yang terdiri dari biaya pakan, biaya tenaga kerja, dan biaya calon induk yang ada di Balai Benih Ikan Lokal Di Desa Cukan Lipai adalah sebagai berikut:

Tabel 2. Biaya Persediaan Induk Ikan Nila, Pakan Ikan, dan Upah Pegawai Balai Benih Ikan Lokal Di Desa Cukan Lipai

\begin{tabular}{|l|l|c|c|c|}
\hline No. & \multicolumn{1}{|c|}{ Bulan } & Induk Ikan(Rp) & Pakan Ikan (Rp) & Upah Pegawai(Rp) \\
\hline 1. & Januari & 868.000 & 550.000 & 382.000 \\
\hline 2. & Februari & 250.000 & 268.000 & 382.000 \\
\hline 3. & Maret & 1.000 .000 & 1.318 .000 & 382.000 \\
\hline 4. & April & 700.000 & 418.000 & 382.000 \\
\hline 5. & Mei & 300.000 & 1.818 .000 & 432.000 \\
\hline 6. & Juni & 1.100 .000 & 4.625 .000 & 432.000 \\
\hline 7. & Juli & 2.842 .000 & 776.000 & 432.000 \\
\hline 8. & Agustus & 3.360 .000 & 567.000 & 482.000 \\
\hline 9. & September & 3.360 .000 & 487.000 & 482.000 \\
\hline 10. & Oktober & 2.292 .000 & 826.000 & 382.000 \\
\hline 11. & November & 1.300 .000 & 857.000 & 382.000 \\
\hline 12. & Desember & 1.528 .000 & 568.000 & 382.000 \\
\hline 13. & Jumlah & 18.900 .000 & 13.078 .000 & 4.934 .000 \\
\hline
\end{tabular}


Penggunaan biaya induk ikan pada Balai Benih Ikan Lokal Di Desa Cukan Lipai Kecamatan Batang Alai Selatan Kabupaten Hulu Sungai Tengah dalam perbulan dapat dilihat dari tabel diatas, selama satu tahun sebesar Rp. 18.900.000. Penggunaan biaya pakan pada Balai Benih Ikan Lokal Di Desa Cukan Lipai dalam perbulan dapat dilihat dari tabel diatas. Besar biaya pakan selama satu tahun sebesar Rp. 13.078.000.

Biaya pakan yang digunakan adalah:

a. Pakan larva

b. Pakan benih

c. Pakan induk

d. Artemia

Penggunaan biaya tenaga kerja pada Balai Benih Ikan Lokal di Desa Cukan Lipai Kecamatan Batang Alai Selatan Kabupaten Hulu Sungai Tengah dalam perbulan dapat dilihat dari tabel diatas. Biaya tenaga kerja perbulan di rataratakan sebesar Rp. 411.000,- dalam satu tahun berjumlah Rp. 4.934.000,-. Upah yang diterima setiap karyawan Balai Benih Ikan Lokal di Desa Cukan Lipai Kecamatan Batang Alai Selatan Kabupaten Hulu Sungai Tengah tiap perbulannya telah di sesuaikan dengan jabatan atau tugas dan pendidikan.

Jabatan atau tugas yang ada di Balai Benih Ikan Lokal

a. Petugas teknis

b. Petugas penanggulangan hama dan penyakit

c. Petugas pemberi pakan pagi

d. Petugas pemberi pakan sore

e. Petugas keamanan

Dari ketiga biaya produksi yang ada di Balai Benih Ikan Lokal Desa Cukan Lipai Kecamatan Batang Alai Selatan Kabupaten Hulu Sungai Tengah tersebut dijumlahkan dalam satu biaya produksi yang telah dikeluarkan untuk keperluan produksi pembenihan ikan nila dari bulan Januari-Desember selama satu tahun dapat dilihat tabel berikut:

Tabel 2. Total Biaya Produksi pada Balai Benih Ikan Lokal Di Desa Cukan Lipai

\begin{tabular}{|c|l|c|}
\hline No. & \multicolumn{1}{|c|}{ Bulan } & Biaya Produksi (Rp) \\
\hline 1. & Januari & 1.800 .000 \\
\hline 2. & Februari & 900.000 \\
\hline 3. & Maret & 2.700 .000 \\
\hline 4. & April & 1.000 .000 \\
\hline 5. & Mei & 4.050 .000 \\
\hline 6. & Juni & 5.157 .000 \\
\hline 7. & Juli & 4.050 .000 \\
\hline 8. & Agustus & 4.409 .000 \\
\hline 9. & September & 4.329 .000 \\
\hline 10. & Oktober & 3.500 .000 \\
\hline 11. & November & 2.539 .000 \\
\hline 12. & Desember & 2.478 .000 \\
\hline & Jumlah & 36.912 .000 \\
\hline
\end{tabular}

Hasil penelitian mengenai biaya produksi pada Balai Benih Ikan Lokal di Desa Cukan Lipai terdiri dari tiga macam biaya produksi yaitu, biaya persediaan induk ikan nila, biaya pakan, biaya tenaga kerja. Nilai rata-rata biaya produksi perbulan adalah sebesar Rp 3.076.000. Pengeluaran biaya produksi di bawah ratarata terjadi pada bulan Januari, Februari, Maret, April, November, dan Desember dikarenakan selama bulan Januari-April terjadi musim hujan dimana kolam tidak terkendala dengan masalah pengairan.

Biaya produksi yang diatas rata-rata terjadi Pada Bulan Mei, Juni, Juli, Agustus, September dan Oktober terjadi kekeringan pada perkolaman yang menyebabkan bibit ikan atau induk ikan banyak yang mati sehingga pihak pembenihan mengeluarkan biaya lebih 
untuk pembenihan ulang atau membeli

induk ikan nila.

\section{Harga Jual}

Tabel 3. Harga Jual ikan nila pada Balai Benih Ikan Lokal Di Desa Cukan Lipai

\begin{tabular}{|c|l|c|c|c|}
\hline No. & \multicolumn{1}{|c|}{ Bulan } & $\begin{array}{c}\text { Harga Jual Per Ekor } \\
(\mathrm{Rp})\end{array}$ & $\begin{array}{c}\text { Volume } \\
\text { Penjualan }\end{array}$ & $\begin{array}{c}\text { Penjualan } \\
(\mathrm{Rp})\end{array}$ \\
\hline 1. & Januari & 125 & 21.496 & 2.687 .000 \\
\hline 2. & Februari & 100 & 12.500 & 1.250 .000 \\
\hline 3. & Maret & 150 & 25.000 & 3.750 .000 \\
\hline 4. & April & 125 & 10.000 & 1.250 .000 \\
\hline 5. & Mei & 125 & 40.000 & 5.000 .000 \\
\hline 6. & Juni & 250 & 24.500 & 6.125 .000 \\
\hline 7. & Juli & 250 & 27.540 & 6.885 .000 \\
\hline 8. & Agustus & 250 & 50.540 & 12.635 .000 \\
\hline 9. & September & 125 & 44.680 & 5.585 .000 \\
\hline 10. & Oktober & 125 & 36.688 & 4.586 .000 \\
\hline 11. & November & 125 & 62.440 & 7.805 .000 \\
\hline 12. & Desember & 300 & 24.240 & 7.272 .000 \\
\hline & Jumlah & & & 64.830 .000 \\
\hline
\end{tabular}

\section{Pengaruh Biaya Produksi Terhadap Harga Jual}

Hasil penelitian mengenai pengaruh biaya produksi terhadap harga jual pada Balai Benih Ikan Lokal di Desa Cukan Lipai terdiri dari tiga macam biaya produksi yaitu, biaya persediaan induk ikan nila, biaya pakan, biaya tenaga kerja, pengaruh biaya produksi terhadap harga jual ini sebesar $37,4 \%$.

Secara keseluruhan persentase tingkat pengeluaran biaya adalah sebagai berikut

Tabel 4. Persentase Biaya Produksi Ikan Nila

\begin{tabular}{|l|lr|c|}
\hline \multicolumn{1}{|c|}{ Jenis Biaya } & \multicolumn{1}{c|}{ Biaya } & Persentase $(\%)$ \\
\hline Biaya Induk Ikan & $\mathrm{Rp}$ & 18.900 .000 & 51,20 \\
\hline Biaya Pakan Ikan & $\mathrm{Rp}$ & 13.078 .000 & 35,43 \\
\hline Biaya Tenaga Kerja & $\mathrm{Rp}$ & 4.934 .000 & 13,36 \\
\hline Total & $\mathrm{Rp}$ & 36.912 .000 & 100 \\
\hline
\end{tabular}


Tabel tersebut menunjukan bahwa biaya produksi yang terendah pada biaya tenaga kerja yaitu sebesar $13,36 \%$, untuk biaya pakan ikan sebesar 35,43\%, sedangkan biaya tertingginya untuk biaya induk ikan yaitu sebesar 51,20\%.

Persentase diatas bahwa penghitungan biaya produksi yang paling terendah yaitu pada biaya tenaga kerja karena upah karyawan tersebut diputusan oleh Kepala Dinas Peternakan dan Perikanan Kabupaten Hulu Sungai Tengah yang disesuaikan dengan petugas teknis dan sesuai jabatannya.

Penelitian pada Balai Benih Ikan Lokal di Desa Cukan Lipai juga terdiri dari tiga macam biaya produksi yaitu, biaya persediaan induk ikan nila, biaya pakan, biaya tenaga kerja, dan pengaruh biaya produksi terhadap harga jual ini sebesar $37,4 \%$ pengaruh biaya produksinya jauh dibawah angka 1 yang artinya tidak terdapat pengaruh nyata tehadap harga jual.

\section{KESIMPULAN}

Nilai $\left(\mathrm{r}^{2}\right)$ yang sebesar 0,374 yang artinya biaya produksi memberikan pengaruh terhadap harga jual sebesar $37,4 \%$, pada usaha pembenihan ikan nila yang berada di desa Cukan Lipai Kecamatan Batang Alai Selatan Kebupaten Hulu Sungai Tengah. Pengaruh variabel (X) yaitu biaya produksi terhadap variabel (Y) harga jual adalah sebesar 37,4\%, sedangkan sisanya $62,6 \%$ bisa dipengaruhi oleh variabel lain yang tidak dimasukan kedalam model persamaan.

\section{DAFTAR PUSTAKA}

Suharno, D.N. 2006. Pengaruh biaya produksi terhadap harga jual pada industri kuningan di Desa Growong Lor Kecamatan Juwana Kabupaten Pati. Skripsi. Universitas Negeri Semarang.

Sulisyanto. 2011. Ekonometrika Terapan. CV. Andi. Yogyakarta.

Supriyono. 1999. Akuntansi Biaya. BPFE. Yogyakarta. 